\title{
In vivo determination of muscle-derived stem cells in rat corpus cavernosum
}

\author{
L.J. Xu, B.X. Xue, Y.X. Shan, D. Chen, J. Gao, D.R. Yang, C.Y. Sun \\ and Y. Cui \\ Department of Urinary Surgery, \\ The Second Affiliated Hospital of Suzhou University, Suzhou, China \\ Corresponding author: Y.X. Shan \\ E-mail: sz2h_syx@126.com
}

Genet. Mol. Res. 14 (3): 9951-9962 (2015)

Received January 13, 2015

Accepted June 10, 2015

Published August 21, 2015

DOI http://dx.doi.org/10.4238/2015.August.21.1

\begin{abstract}
The aim of this in vivo study was to determine the existence of muscle-derived stem cells (MDSCs) in rat corpus cavernosum. Immunohistochemical and RT-PCR analyses were performed to determine the expression of the stem cell markers (Sca1, Oct4, and desmin) in Sprague-Dawley (SD) rats in different age groups (10 rats in each group). Sca-1 was mainly expressed in blood vessels and cavernous sinus and demonstrated primarily cytoplasmic staining. Desmin was expressed mainly in muscle tissues and staining occurred mainly in the cytoplasm but also partially in the nucleus. An extremely small amount of double-positive stained cells (Sca-1/desmin) were detected near the cavernous sinus. Expression of the markers was significantly and negatively correlated with the age of the rats $(\mathrm{P}<0.05)$. The RT-PCR results showed that the expression levels of Sca-1 and desmin significantly decreased with age $(\mathrm{P}<0.05)$. Correlation analysis indicated that the expression of Sca-1 and desmin were significantly and negatively correlated with the age of rats $(r=-0.929, \mathrm{P}<0.05)$. The present study provides evidence for the existence of MDSCs in rat corpus cavernosum.
\end{abstract}


MDSCs may have therapeutic potential in the treatment of organic erectile dysfunction.

Key words: Muscle-derived stem cells; Rat corpus cavernosum; Stem cell markers; Erectile dysfunction

\section{INTRODUCTION}

Adult stem cells play a critical role in basic research and the clinical treatment of many diseases (Trounson, 2009). Adult stem cells are capable of trans-system and trans-mesoderm differentiation and for this reason these cells have been extensively studied for a variety of diseases, including erectile dysfunction (ED) (Albersen et al., 2010; Kim et al., 2011a). However, the characterization and distribution of endogenous stem cells in cavernosum tissue have not been fully elucidated, so exogenous stem cells must be used for investigations into cellular therapeutics for ED (Nolazco et al., 2008; Lin et al., 2009). These exogenous cells include embryonic stem cells, mesenchymal stem cells, adipose stem cells, muscle-derived stem cells, neural crest stem cells, and other stem cells (Jackson et al., 2007). Although there are a multitude of exogenous cells that can be used, the development of these cells has been limited due to the complexity and invasiveness of the treatment process (Ambrosio et al., 2009; Kim et al., 2011b). Non-invasive methods and investigations into the expression of endogenous stem cells in cavernosum are paramount to successful cellular ED interventions (Song et al., 2007).

The functional unit for erection is smooth muscle fiber and the sinusoidal endothelial cell system (Andersson, 2011). The smooth muscles account for $40-50 \%$ of cavernosum tissue and play an important role in erectile function (Moreland et al., 2001; Sullivan et al., 2001). Due to their critical role, cavernosum muscle-derived stem cells (MDSCs) were chosen as the target cells in the present study. In recent years, MDSCs have been widely used for investigations into the treatment of muscular dystrophy (Ambrosio et al., 2009), heart disease (Shibuya et al., 2010), stress urinary incontinence (Proano et al., 2010), neurogenic bladder (Nitta et al., 2010), and bone and nervous system diseases (Matsumoto et al., 2009; Xu et al., 2010). Despite their widespread use, treatments for organic ED by interfering with and regulating the expression of cavernosum MDSCs have not been reported.

The aim of this project was to investigate the existence of cavernosum MDSCs. MDSCs are mainly obtained through short-cycle enzymatic digestion, which offers easy access and low contamination rates. The pre-plate differential adhesion technique was used for separation and purification (Gharaibeh et al., 2008; Nolazco et al., 2008). Since specific markers are still unavailable for the identification of MDSCs, we utilized frequently used stem cell markers, namely Sca-1, Oct4, and desmin, for their identification (Nolazco et al., 2008; Shi and Jin, 2010; Lam et al., 2011). The present study utilized immunohistochemical and RT-PCR techniques to detect the expression of Sca-1 and desmin in the cavernosum of rats of varying ages as well as to investigate the distribution of MDSCs in the cavernosum tissue. The enzymatic digestion method and an improved pre-plate differential adhesion method were used to separate and purify cavernosum cells of rats. Immunofluorescence cytochemistry, flow cytometry and Western blots were used to determine the expression of Sca-1, Oct4, and desmin in adherent cells, and to further explore the related techniques for initial separation of MDSCs. The results from these experiments will provide the experimental basis for further 
subculture of MDSCs and induced differentiation, and provide potential therapeutic strategies for the stem cell based therapy in organic ED.

\section{MATERIAL AND METHODS}

\section{Ethics statement}

The study was approved by the Ethics Committee of the Second Affiliated Hospital of Suzhou University. All animals received humane care in compliance with the "Principles of Laboratory Animal Care" (NIH publication No. 85-23, revised 1985). All animal experiments were approved by the Animal Care and Use Committee of Binzhou Medical College.

\section{Animals and treatments}

Thirty male SD rats of two, five, and twenty months from different nests were randomly selected (clean grade) and their average body weights were 180, 370, and $520 \mathrm{~g}$, respectively. The rats were purchased from the Center of Experimental Animals in Suzhou University, and they were operationally defined as the young group $(\mathrm{N}=10)$, mid-age group ( $\mathrm{N}$ $=10)$, and old group $(\mathrm{N}=10)$. The rats were subjected to anesthesia by ether inhalation and an incision was made in the lower portion of the abdomen. The penile tissues were carefully separated and dissected. The penis head (including the penis cartilage) and urethral sponge were removed and the corpus cavernosum was collected. After rinsing with normal saline, the tissues were divided into two parts. The first part was immersed in 10\% neutral formalin solution for fixation, hematoxylin-eosin (HE) staining and immunohistochemical analysis. The second part was immediately placed in liquid nitrogen for storage and later RT-PCR.

\section{Immunohistochemical analysis}

Three serial sections of the cavernosum tissues were dehydrated, embedded and then serial sections in paraffin with a thickness of $4 \mu \mathrm{m}$. The EnVision method was used for single immunohistochemical labeling of Sca-1 and desmin. The EnVision-HR method was further utilized for double immunohistochemical labeling of Sca-1/desmin. PBS was used instead of the primary antibody as the blank control.

\section{RT-PCR}

The primer sequences were designed using the Primer Premier 5.0 software and the housekeeping gene $\beta$-actin was used as an internal reference (Table 1). The RT reaction mixture $(30 \mu \mathrm{L})$ contained $15 \mu \mathrm{L} 2 \mathrm{X}$ RT buffer, $1 \mu \mathrm{L} 100 \mu \mathrm{M}$ random primers, $1 \mu \mathrm{L}$ RTase, $6 \mu \mathrm{L}$ template (RNA), and $7 \mu \mathrm{L} \mathrm{DEPC}$ water. The reaction conditions were as follows: $25^{\circ} \mathrm{C}$ for 10 $\min , 40^{\circ} \mathrm{C}$ for $60 \mathrm{~min}$, and $70^{\circ} \mathrm{C}$ for $10 \mathrm{~min}$. The fluorescence quantitative RT-PCR mixture $(50$ $\mu \mathrm{L}$ ) contained $25 \mu \mathrm{L} 2 \mathrm{X}$ PCR buffer, $0.6 \mu \mathrm{L}$ of each primer $(25 \mu \mathrm{M}), 1 \mu \mathrm{L}$ template (cDNA), $22.8 \mu \mathrm{L}$ DEPC water. The amplification conditions were as follows: $94^{\circ} \mathrm{C}$ pre-denaturation for $3 \mathrm{~min}, 94^{\circ} \mathrm{C}$ for $25 \mathrm{~s}, 60^{\circ} \mathrm{C}$ for $25 \mathrm{~s}$, and $72^{\circ} \mathrm{C}$ for $25 \mathrm{~s}$ for 35 cycles. The product was analyzed by $2 \%$ agarose gel electrophoresis. 
Table 1. Primer sequences for the detection on mRNA expression level and product length.

\begin{tabular}{lllc}
\hline Gene & Sense chain & Anti-sense chain & Product length (bps) \\
\hline$\beta$-actin & CCCATCTATGAGGGTTACGC & TTTAATGTCACGCACGATTTC & 150 \\
Sca-1 & AACCATATTTGCCTTCCCGTCT & CCAGGTGCTGCCTCCAGTG & 135 \\
Desmin & CTTGATGAGGCAGATGAGGA & AGCTTCCGGTAGGTGGCAAT & 192 \\
\hline
\end{tabular}

\section{Digestion and separation of corpus cavernosum cells}

After anesthetizing the animals, the penile tissue was collected under sterile conditions from the 2-month-old male SD rats. All operations were performed on an ultraclean bench. PBS was used to rinse the tissues three times. The penis skin, subcutaneous fascia, urethra, and albuginea were carefully removed using sterile ophthalmic scissors, and the corpus cavernosum tissues were kept. The cavernous tissues were cut into small 1.0-2.0 $\mathrm{mm}^{3}$ sections and enzymatic digestion was used for digestion and separation. 0.5\% type I collagenase was added for the digestion at constant temperature for $3 \mathrm{~h}$. Afterwards, $0.1 \%$ trypsin in the same volume was added for further digestion for another $30 \mathrm{~min}$. The cells were then examined under the microscope, and DMEM high sugar medium containing $10 \%(\mathrm{v} / \mathrm{v})$ fetal bovine serum was added to terminate the digestion when the cells were nearly all dispersed into single cells. The solution was then filtered using a 200 mesh filter, and then $200 \mathrm{~g}$ of filtrate was collected by centrifuging at $200 \mathrm{~g}$ for $10 \mathrm{~min}$. The supernatant was discarded and the cell pellet was resuspended in DMEM medium containing $20 \%$ fetal bovine serum. The cell concentration was adjusted and the cells were inoculated into cell culture flasks and incubated at $37^{\circ} \mathrm{C}$ in a $5 \%(\mathrm{v} / \mathrm{v}) \mathrm{CO}_{2}$ incubator.

\section{Purification and culture of cells}

The contaminated cells were removed using the Pre-plate differential adhesion method (Qu-Petersen et al., 2002). These cells were grown for one hour and the adherent cells were Pre-plate 1 (PP1). The non-adherent cells were grown in a new culture flask for another two hours, and the adherent cells were considered Pre-plate 2 (PP2). Again the non-adherent cell suspension was transferred to a new flask for further growth for $18 \mathrm{~h}$, and the subsequent adherent cells were considered Pre-plate 3 (PP3). Afterwards, flask culture transfers were performed every $24 \mathrm{~h}$, and the cells were successively identified as Pre-plate 4 to 6 , respectively (PP4, PP5, and PP6). PP6 cells began to adhere to the wall after they were grown for two or three days, and the culture solution was changed once a day. The cells were observed under an inverted microscope, and the cells were divided and grown in different flasks when cell confluence approached $50 \%$. These cells were then used for the subsequent experiments.

\section{Flow cytometry analysis}

PP6 cells were collected and the cell concentration was adjusted to $1 \times 10^{7}$ cells $/ \mathrm{mL}$. The cells were fixed for $15 \mathrm{~min}$ by the addition of $100 \mu \mathrm{L}$ Reagent $\mathrm{A}$ and were then rinsed once with PBS. The cells were subsequently centrifuged and collected, and the primary antibody (Sca-1, Oct4, and desmin; 1:50) was added. The IgG corresponding to the primary antibody was then added in the control group and fully mixed with the cells. After incubation at room temperature for $40 \mathrm{~min}$, the cells were rinsed twice with PBS. Afterwards, the FITC-labeled 
secondary antibody corresponding to the primary antibody (1:50) was added. After incubation at room temperature in the dark for $30 \mathrm{~min}$, the cells were rinsed with PBS and $500 \mu \mathrm{L}$ PBS was added. Flow cytometry was used to determine the positive cell count.

\section{Immunofluorescence cytochemical identification}

The PP6 cells were inoculated on a six-well plate with coverslip. Growth coverslips were prepared after the adherence of the cells. The cells were fixed with $40 \mathrm{~g} / \mathrm{L}$ paraformaldehyde for two hours and then flooded and rinsed with PBS. Afterwards, 1\% Triton-100 was added and the cells were kept at room temperature for $15 \mathrm{~min}$. The cells were then flooded and rinsed with PBS. The growth coverslips were treated with $3 \%(\mathrm{v} / \mathrm{v}) \mathrm{H}_{2} \mathrm{O}_{2}$-methanol solution for $15 \mathrm{~min}$, after which the cells were flooded and rinsed with PBS. Primary antibody, $100 \mu \mathrm{L}$, was added (stem cell antigen 1, embryonic antigen, desmin 1:50), and the cells were incubated at $37^{\circ} \mathrm{C}$ for $2 \mathrm{~h}$ (the two kinds of primary antibodies were added simultaneously for Sca-1/ Oct4, Sca-1/desmin, and Oct4/desmin double immunofluorescence cytochemical analysis). PBS was used instead of the primary antibody as the negative control and the specimens were flooded and rinsed with PBS. FITC-labeled secondary antibody $(1: 200,100 \mu \mathrm{L})$ corresponding to the primary antibody was added, and the cells were incubated at $37^{\circ} \mathrm{C}$ for $1 \mathrm{~h}$ (the two kinds of secondary antibodies corresponding to the primary antibody were added simultaneously at the same time of being labeled by double-label immunofluorescence method). PBS was used to immerse and rinse the cells and the mounting medium preventing fluorescence quenching was used. The specimens were then observed and photographed under a fluorescence microscope. The images were processed using the Image-ProPLUS software.

\section{Western blotting}

PP1-PP6 cells were collected, and a total protein extraction kit was used to extract the proteins in different samples. The Bradford method was used to determine the protein concentrations of the different samples, and the loading amount was adjusted. Electrophoresis was performed using an SDS-PAGE gel. The proteins were transferred to a PVDF membrane and blocked using a blocking buffer. After this step, the primary antibody (Sca-1, Oct4, and Desmin; 1:400) was added and the membrane was incubated on a shaker at $4^{\circ} \mathrm{C}$ overnight. The secondary antibody (HRP-goat anti-rabbit IgG, HRP-sheep anti-mouse IgG, diluted with the blocking buffer at 1:5000) was then added after the membrane was rinsed, and then the membrane was exposed after developing.

\section{Determination of positive results}

The immunohistochemical results were collected from the different groups analyzed under the microscope (400X). The positive staining result for single labeling was brown and the positive staining results for double labeling was dark brown.

\section{Statistical analyses}

The data are reported as the means \pm standard deviation (means $\pm \mathrm{SD}$ ). $t$-tests were 
used to determine differences between groups, and $\mathrm{P}<0.05$ was considered to be statistically significant. Spearman rank correlation was used for correlation analysis and $\mathrm{P}<0.05$ indicated a significant correlation.

\section{RESULTS}

\section{HE staining}

The corpus cavernosum of the rats gradually changed from tightly organized structures to loosely organized structures as the age of the rats increased. Similarly, the blood vessels were found to be abundant, slightly decreased, and significantly decreased in the young, mid-age and old rats (Figure 1).
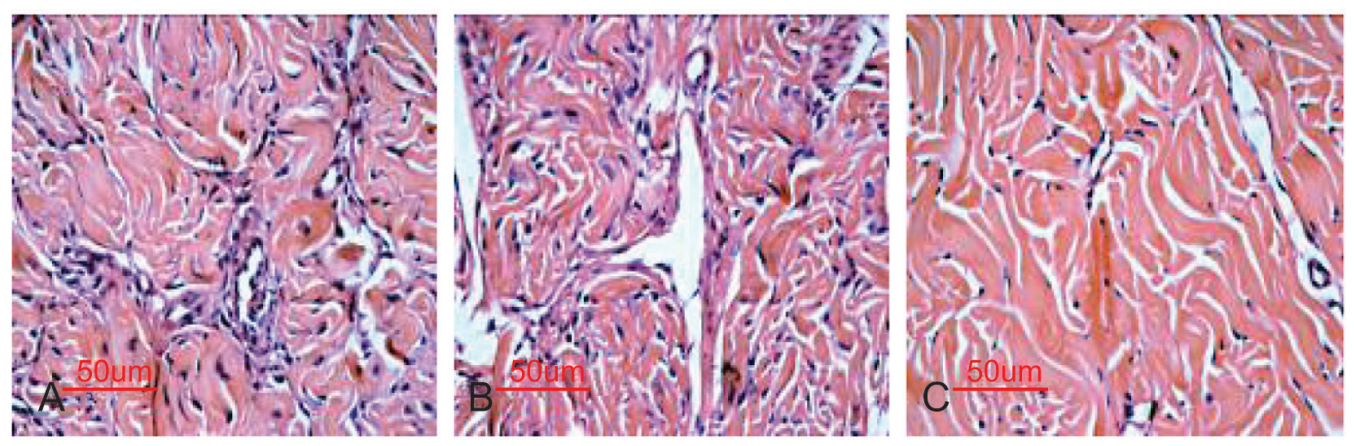

Figure 1. Differences in structural density of corpus cavernosum and the distribution of blood vessels in the SD rats of at different month-old groups: Young (A), Mid-age (B), and Old (C) groups (400X).

\section{Immunohistochemical results}

The results showed the following features. 1) Sca-1 was mainly expressed in blood vessels and the cavernous sinus, with staining primarily in the cytoplasm. 2) Desmin was expressed mainly in muscle tissues, with staining mainly in the cytoplasm but also partially in the nucleus. 3) An extremely small number of double-positive stained cells (Sca-1/desmin) were detected near the cavernous sinus. 4) There were statistically significant differences in the expression of Sca-1 and desmin between the age groups $(\mathrm{P}<0.05)$. Expression of the markers was significantly and negatively correlated with the age of the rats $(\mathrm{P}<0.05)$ (Figures 2 and 3 ).

\section{RT-PCR results}

The RT-PCR results showed that the expression levels of Sca-1 and desmin significantly decreased with age $(\mathrm{P}<0.05)$. There were significant differences in the concentrations of the two kinds of markers between age groups $(\mathrm{P}<0.05)$ (Table 2$)$, which was in accordance with the immunohistochemical results. 

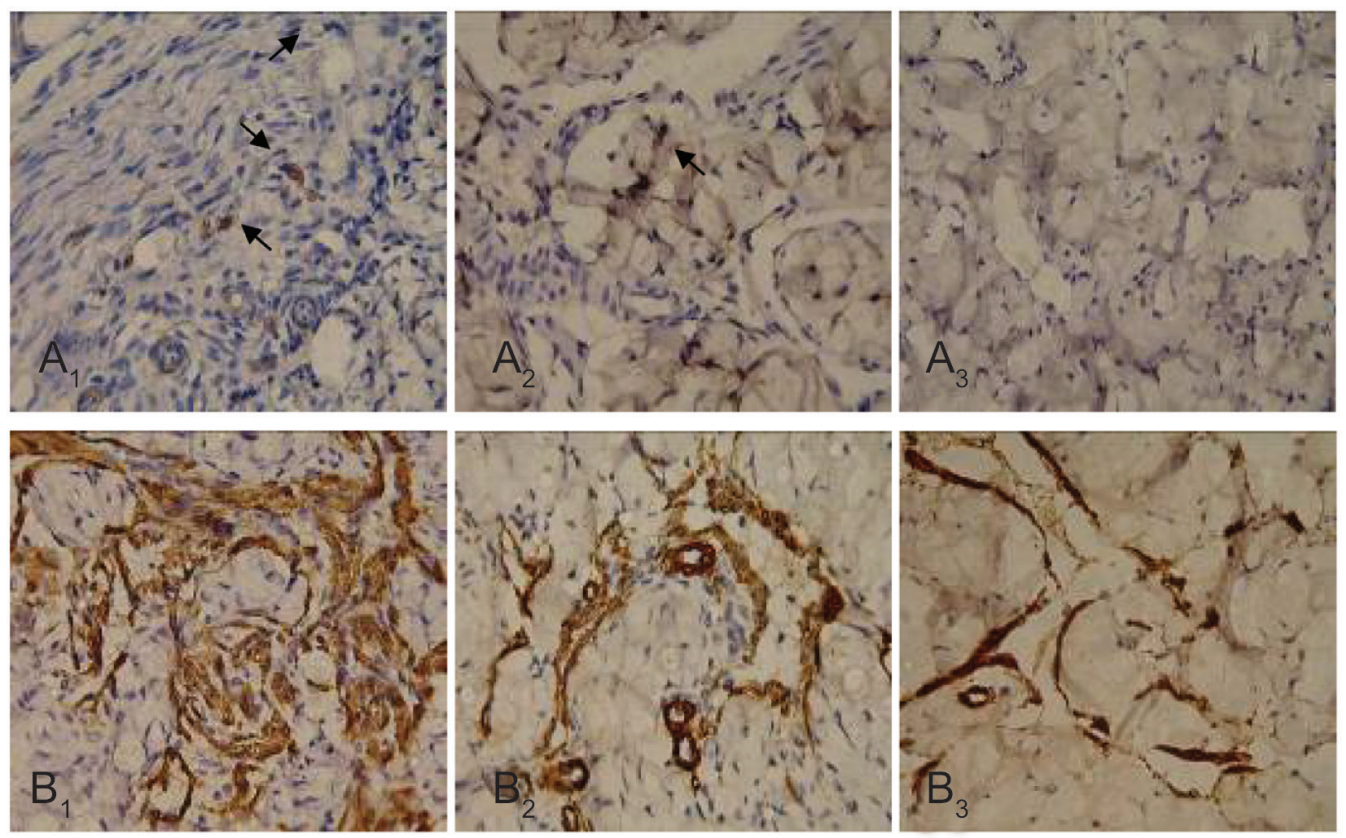

Figure 2. Expression of Sca-1 and Desmin in the corpus cavernosum of the SD rats of different ages (400X). A. and B. correspond to Sca-1 and Desmin, respectively and 1, 2, 3 correspond to the young, mid-age, and the old group, respectively. The arrows point to positively stained cells.
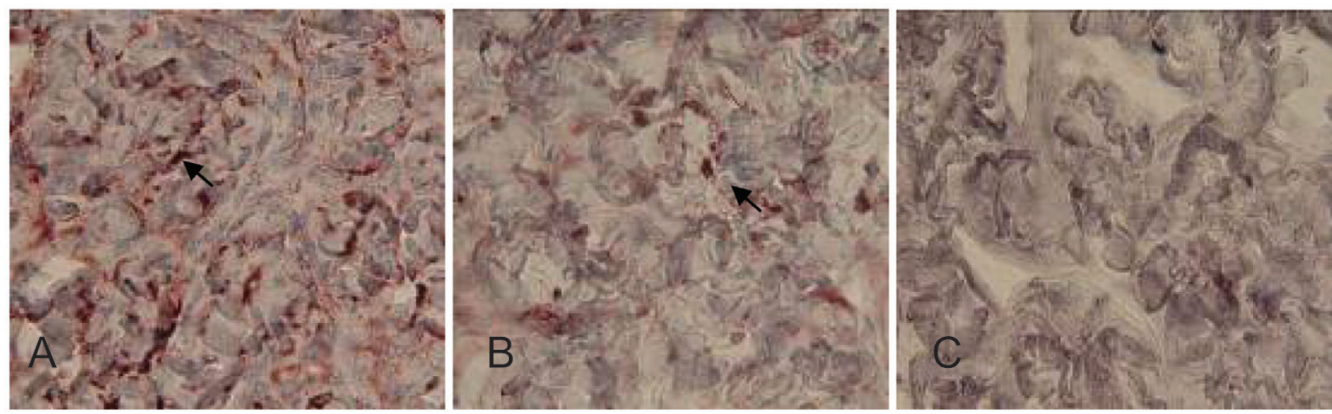

Figure 3. Expression of Sca-1/Desmin in the corpus cavernosum of the SD rats of different ages (400X). A. B. and C. correspond to the young, mid-age, and the old group, respectively. The arrows point to positively stained cells.

Table 2. Expression levels of Sca-1 and Desmin in corpus cavernosum of the rats from different age groups.

\begin{tabular}{lccc}
\hline Groups & Young group & Mid-age group & Old group \\
\hline Sca-1 & $0.55 \pm 0.07$ & $0.27 \pm 0.04^{*}$ & $0.14 \pm 0.02^{* \Delta}$ \\
Desmin & $3.40 \pm 0.31$ & $2.10 \pm 0.23^{*}$ & $1.10 \pm 0.24^{* \Delta}$ \\
\hline
\end{tabular}

*Compared with the young group $\mathrm{P}<0.05 .{ }^{\wedge}$ Compared with the mid-age group $\mathrm{P}<0.05$. 


\section{Correlation analysis for the amount of stem cell marker and the age of rats}

Correlation analysis indicated that the expression of Sca-1 was significantly and negatively correlated with the age of rats $(r=-0.929, \mathrm{P}<0.05)$. Similarly, the expression of desmin was significantly and negatively correlated with the age of rats $(\mathrm{r}=-0.924, \mathrm{P}<0.05)$.

\section{Results of cell isolation and flow cytometry}

PP1 and PP2 cells adhered to the wall rapidly and they were mainly long spindleshaped fibrous cells. The adherent capability of PP3-PP5 cells successively decreased. In these plates, short spindle-shaped cells appeared. Some of these cells were polygon-shaped and primarily consisted of vascular endothelial and smooth muscle cells. Some of the PP6 cells were small and round floating cells. These PP6 cells slowly adhered to the wall and became adherent as round- or spindle-shaped cells after two or three days (Figure 4). The expression of Sca-1, Oct4, and desmin in PP6 cells was 5.7, 2.6, and 41.2\%, respectively.
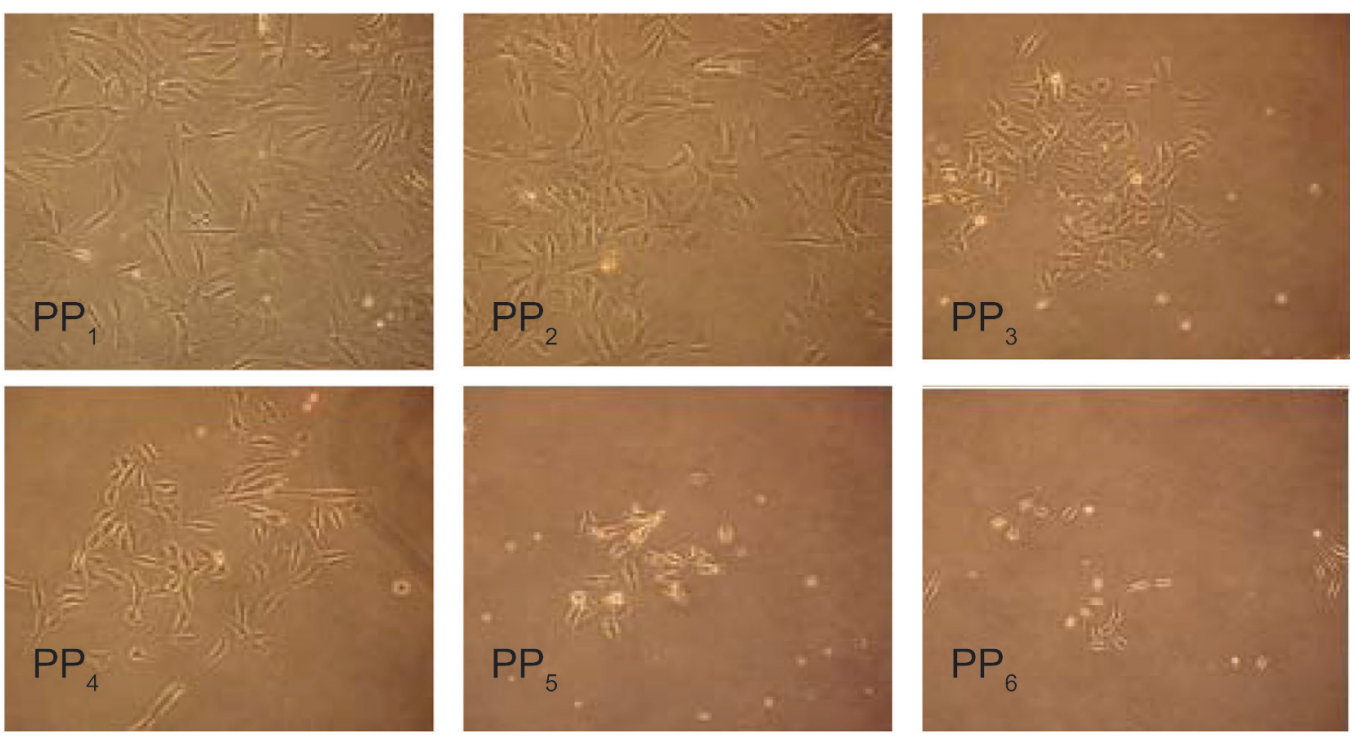

Figure 4. Morphology of PP1-PP6 cells under the light microscope (400X).

\section{Immunofluorescence cytochemistry results}

The expression of Sca-1, Oct4, and desmin was detected in PP6 cells, while the expression of Sca-1 and Oct4 was detected in very few cells. Sca-1 was mainly expressed in the cytoplasm, Oct4 was mainly expressed in the nucleus, and desmin $(+)$ was concentrated and mainly expressed in the cytoplasm (Figure 5). Very few cells expressed Sca-1/Oct4, Sca-1/ desmin, and Oct4/desmin. Sca-1/Oct4 was expressed in the cytoplasm and the nucleus, Sca-1/ desmin mainly in the cytoplasm, and Oct4/desmin mainly in the nucleus and cytoplasm. 


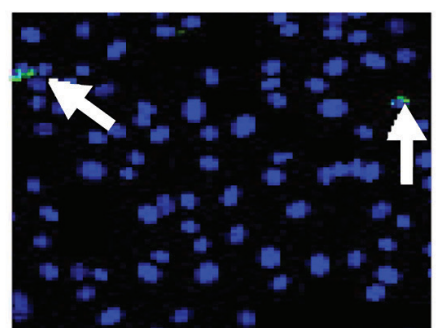

a:Sca-1

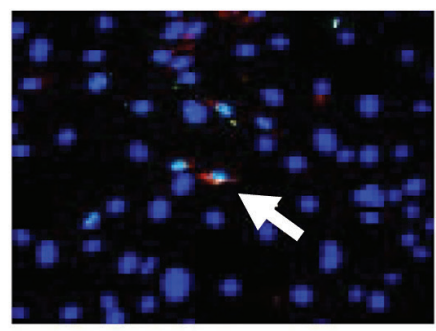

e:Sca-1/Oct4

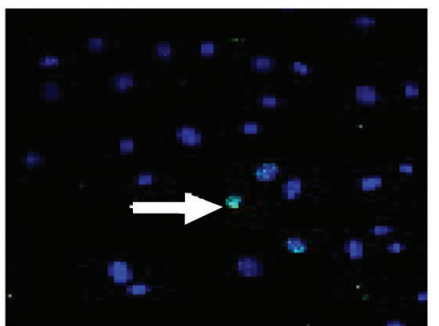

b:Qct4

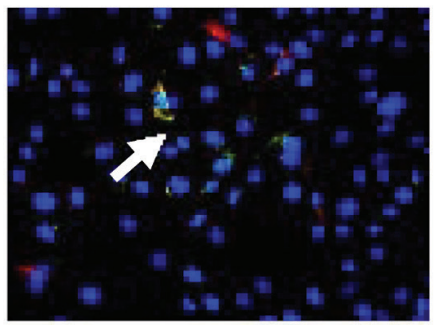

e:Sca-1/Desmin

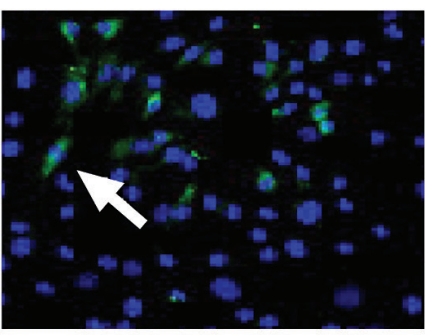

c:Desmin

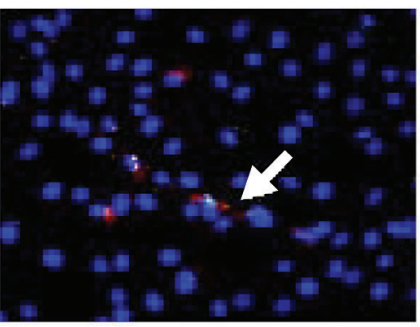

f:Ot4/Desmin

Figure 5. Expression of Sca-1, Oct4, Desmin, Sca-1/Oct4, Sca-1/Desmin, and Oct4/Desmin in the PP6 cells. The arrows indicated positive cells (400X).

\section{Western blotting results}

When the total amount of protein was equivalent, significant expression levels of Sca1 and Oct4 were not detected in the PP1-PP5 cells. The expression of Sca-1 and Oct4 was detected in the PP6 cells and the concentrations were lower than that of the internal reference. A very low expression level of desmin was detected in PP1-PP2 cells, while its expression level significantly increased in the PP3-PP6 cells (Figure 6).

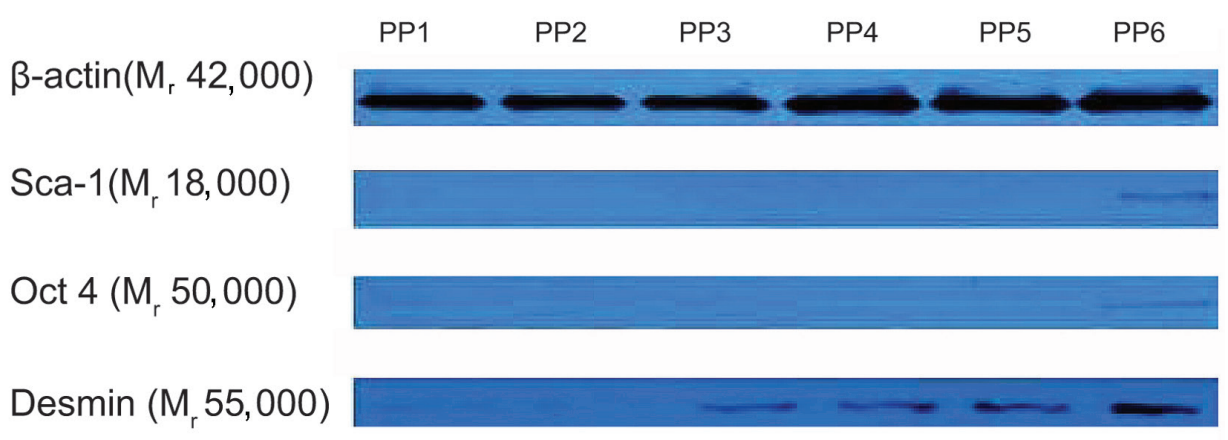

$\beta$-actin: an internal control

Figure 6. Western blotting detection of Sca-1, Oct4, and Desmin expression in PP1-PP6 cells. 


\section{DISCUSSION}

The present study investigated the expression and distribution of Sca-1, desmin, and Sca-1/desmin in corpus cavernosum of rats. We also found that the expression levels were significantly negatively correlated with the age of the rats, suggesting that the expression of these markers gradually decreases with age. As part of this investigation, the corpus cavernosum cells were also isolated and purified to determine the expression of Sca-1, Oct4, desmin, Sca-1/Oct4, Sca-1/desmin, and Oct4/desmin. These data provided the experimental evidence for further subculture and amplification of MDSCs, and also provided evidence for possible therapeutic strategies for non-invasive stem cell based therapy in organic ED.

The present study made use of important techniques to isolate MDSCs in these tissues. This is an important step in investigations of this type. We processed the corpus cavernosum tissues using enzymatic digestion, and the modified corpus Pre-plate differential adhesion technique was further utilized to isolate and purify the MDSCs according to Qu-Petersen et al. (2002) and Nieponice et al. (2008). The Pre-plate technique provides investigators with a rather homogenous sample of stem cells (Becker and Jakse, 2007). The adhesive capability of fibroblasts and collagen fiber cells was the greatest, so these cells were primarily isolated on the plate. As the adhesive capability of vascular endothelial cells and smooth muscle cells was relatively lower, these cells adhered on the later plates. MDSCs had the lowest adhesion capability, so after continuous six-step differential adhesion, most of the impurity cells were removed and the efficiency in the detection could be improved in the final sample of cells. The isolated PP6 cells in the present study were small round or short fusiform shaped cells and their adhesive capability was relatively weak, which was consistent with the characteristics of MDSCs.

The present study detected the expression of Sca-1 and Oct4 in cavernous tissue and cells and the results were similar to the findings from non-corpus cavernosum-derived MDSCs reported by Nieponice et al. (2008) and Ho et al. (2009). The techniques presented in the present study can be used with previously established methods to identify corpus cavernosum stem cells and improve in their identification rate.

Previous investigations have indicated that the positive rate of desmin in MDSCs can be as high as $90 \%$. Therefore, desmin is frequently used for the identification of MDSCs (Danisovic et al., 2008). This experiment detected a very low level of double-positive cells (Sca-1/ desmin) near the cavernous sinus. The double-positive cells (Sca-1/Oct4, Sca-1/desmin, Oct4/ desmin) were successfully isolated, which further confirmed that MDSCs existed in the stem cells from corpus cavernosum. It should be noted that endothelial, vascular, neurological and other factors also play an important role in the pathogenesis of organic ED (Lippi et al., 2012). While MDSCs have the multiple differentiation capability of stem cells, they cannot only differentiate into myogenic cells, but also have a very high potential for endothelial, vascular and neural differentiation. Therefore, these cells may play an important role in future clinical treatment approaches.

Another important finding of this study was the relationship between the expression of the markers and the age of the rats. As the rats grew older, the expression of the markers significantly decreased. This suggests that the collection of stem cells from corpus cavernosum of rats should be carried out in young rats. In addition, the efficacy of based therapy in ED using endogenous stem cells may be closely related to the age of patients. Therapeutic efficacy in middle-age and younger patients may be better than that in older patients. 
This study provides an important foundation for future research that targets cellular treatments for ED. In this study, we detected and isolated corpus cavernosum MDSCs at the tissue level, which is a promising first step for future treatments of ED using endogenous stem cells. However, the subculture amplification, multiple-direction induced differentiation and functional tests on animal models require further investigation before conclusions can be made about the viability of the MDSC approach. The incidence of diabetic-related ED has increased in recent years and has been attributed to structural impairments in endothelial cells, decreased smooth musco3 cells and cavernous nerve injury (Angeloni et al., 2011; Li et al., 2011). However, the potent self-renewing and proliferative capability of MDSCs, as well as the multi-direction differentiation potency, has a broad prospective in the treatment of diabetic ED. Some studies have proposed that the endogenous organ stem cells can be activated by proper ultrasonic treatments in the distribution region of stem cells (Wang et al., 2010). This may provide a feasible treatment paradigm for the non-invasive based therapy of organic ED using stem cells in the future.

\section{Conflicts of interest}

The authors declare no conflict of interest.

\section{ACKNOWLEDGMENTS}

We acknowledge the helpful comments on this paper received from the reviewers. We also thank all of our colleagues working in the Department of Urinary Surgery, the Second Affiliated Hospital of Suzhou University.

\section{REFERENCES}

Albersen M, Fandel TM, Lin G, Wang G, et al. (2010). Injections of adipose tissue-derived stem cells and stem cell lysate improve recovery of erectile function in a rat model of cavernous nerve injury. J. Sex. Med. 7: 3331-3340.

Ambrosio F, Ferrari RJ, Fitzgerald GK, Carvell G, et al. (2009). Functional overloading of dystrophic mice enhances muscle-derived stem cell contribution to muscle contractile capacity. Arch. Phys. Med. Rehabil. 90: 66-73.

Andersson KE (2011). Mechanisms of penile erection and basis for pharmacological treatment of erectile dysfunction. Pharmacol. Rev. 63: 811-859.

Angeloni NL, Bond CW, Tang Y, Harrington DA, et al. (2011). Regeneration of the cavernous nerve by Sonic hedgehog using aligned peptide amphiphile nanofibers. Biomaterials 32: 1091-1101.

Becker C and Jakse G (2007). Stem cells for regeneration of urological structures. Eur. Urol. 51: 1217-1228.

Danisovic L, Varga I, Polak S, Ulicna M, et al. (2008). Morphology of in vitro expanded human muscle-derived stem cells. Biomed. Pap. Med. Fac. Univ. Palacky Olomouc Czech Repub. 152: 235-238.

Gharaibeh B, Lu A, Tebbets J, Zheng B, et al. (2008). Isolation of a slowly adhering cell fraction containing stem cells from murine skeletal muscle by the preplate technique. Nat. Protoc. 3: 1501-1509.

Ho MH, Heydarkhan S, Vernet D, Kovanecz I, et al. (2009). Stimulating vaginal repair in rats through skeletal musclederived stem cells seeded on small intestinal submucosal scaffolds. Obstet. Gynecol. 114: 300-309.

Jackson L, Jones DR, Scotting P and Sottile V (2007). Adult mesenchymal stem cells: differentiation potential and therapeutic applications. J. Postgrad. Med. 53: 121-127.

Kim BJ, Jin HK and Bae JS (2011a). Bone marrow-derived mesenchymal stem cells improve the functioning of neurotrophic factors in a mouse model of diabetic neuropathy. Lab. Anim. Res. 27: 171-176.

Kim EK, Li G, Lee TJ and Hong JP (2011b). The effect of human adipose-derived stem cells on healing of ischemic wounds in a diabetic nude mouse model. Plast. Reconstr. Surg. 128: 387-394.

Lam ML, Hashem SI and Claycomb WC (2011). Embryonic stem cell-derived cardiomyocytes harbor a subpopulation of niche-forming Sca-1+ progenitor cells. Mol. Cell Biochem. 349: 69-76. 
Li WJ, Zhou J, Li B, Wang H, et al. (2011). PARP inhibition restores erectile function by suppressing corporal smooth muscle apoptosis in diabetic rats. J. Sex. Med. 8: 1072-1082.

Lin G, Banie L, Ning H, Bella AJ, et al. (2009). Potential of adipose-derived stem cells for treatment of erectile dysfunction. J. Sex. Med. 6 (Suppl 3): 320-327.

Lippi G, Plebani M, Montagnana M and Cervellin G (2012). Biochemical and genetic markers of erectile dysfunction. Adv. Clin. Chem. 57: 139-162.

Matsumoto T, Cooper GM, Gharaibeh B, Meszaros LB, et al. (2009). Cartilage repair in a rat model of osteoarthritis through intraarticular transplantation of muscle-derived stem cells expressing bone morphogenetic protein 4 and soluble Flt-1. Arthritis Rheum. 60: 1390-1405.

Moreland RB, Hsieh G, Nakane M and Brioni JD (2001). The biochemical and neurologic basis for the treatment of male erectile dysfunction. J. Pharmacol. Exp. Ther. 296: 225-234.

Nieponice A, Soletti L, Guan J, Deasy BM, et al. (2008). Development of a tissue-engineered vascular graft combining a biodegradable scaffold, muscle-derived stem cells and a rotational vacuum seeding technique. Biomaterials 29: 825-833.

Nitta M, Tamaki T, Tono K, Okada Y, et al. (2010). Reconstitution of experimental neurogenic bladder dysfunction using skeletal muscle-derived multipotent stem cells. Transplantation 89: 1043-1049.

Nolazco G, Kovanecz I, Vernet D, Gelfand RA, et al. (2008). Effect of muscle-derived stem cells on the restoration of corpora cavernosa smooth muscle and erectile function in the aged rat. BJU Int. 101: 1156-1164.

Proano AR, Medrano A, Garrido G and Mazza O (2010). Muscle-derived stem cell therapy for stress urinary incontinence. Actas Urol. Esp. 34: 15-23.

Qu-Petersen Z, Deasy B, Jankowski R, Ikezawa M, et al. (2002). Identification of a novel population of muscle stem cells in mice: potential for muscle regeneration. J. Cell Biol. 157: 851-864.

Shi G and Jin Y (2010). Role of Oct4 in maintaining and regaining stem cell pluripotency. Stem. Cell Res. Ther. 1: 39.

Shibuya M, Miura T, Fukagawa Y, Akashi S, et al. (2010). Tongue muscle-derived stem cells express connexin 43 and improve cardiac remodeling and survival after myocardial infarction in mice. Circ. J. 74: 1219-1226.

Song YS, Lee HJ, Park IH, Kim WK, et al. (2007). Potential differentiation of human mesenchymal stem cell transplanted in rat corpus cavernosum toward endothelial or smooth muscle cells. Int. J. Impot. Res. 19: 378-385.

Sullivan ME, Keoghane SR and Miller MA (2001). Vascular risk factors and erectile dysfunction. BJU Int. 87: 838-845.

Trounson A (2009). New perspectives in human stem cell therapeutic research. BMC Med. 7: 29.

Wang S, Li Y, Ji YC, Lin CM, et al. (2010). Stem-cell-activated organ following ultrasound exposure: better transplant option for organ transplantation. Med. Hypotheses 74: 147-149.

Xu Y, Song YF and Lin ZX (2010). Transplantation of muscle-derived stem cells plus biodegradable fibrin glue restores the urethral sphincter in a pudendal nerve-transected rat model. Braz. J. Med. Biol. Res. 43: 1076-1083. 